\title{
Improving the performance of nadolol stereoisomers' preparative separation using Chiralpak IA by SMB chromatography
}

\author{
Rami S. Arafah ${ }^{1,2}$ (D) | António E. Ribeiro ${ }^{1,2}$ (D) | Alírio E. Rodrigues ${ }^{3}$ (D) | Luís S. Pais ${ }^{1,2}$ (D)
}

${ }^{1}$ Centro de Investigação de Montanha (CIMO), Instituto Politécnico de Bragança, Bragança, Portugal

${ }^{2}$ Laboratory of Separation and Reaction Engineering, School of Technology and Management, Polytechnic Institute of Bragança, Bragança, Portugal

${ }^{3}$ Laboratory of Separation and Reaction Engineering Department of Chemical Engineering Faculty of Engineering, University of Porto, Porto, Portugal

\section{Correspondence}

Luís S. Pais, Centro de Investigação de Montanha (CIMO), Instituto Politécnico de Bragança, Campus de Santa Apolónia, 5300-253 Bragança, Portugal.

Email: pais@ipb.pt

\section{Funding information}

Fundação para a Ciência e a Tecnologia (FCT); Associate Laboratory LSRE-LCM, Grant/Award Number: POCI-01-0145FEDER-006984; European Regional Development Fund (ERDF); Norte Portugal Regional Operational Programme (NORTE 2020), Grant/Award Number: NORTE-01-0145-FEDER-000006

\begin{abstract}
The pseudobinary preparative separation of nadolol stereoisomers is performed by simulated moving bed chromatography (SMB). Using the Chiralpak IA adsorbent, a new 25:75:0.1 ( $/ / v / v)$ methanol-acetonitrile-diethylamine solvent composition was selected to perform the experimental SMB separation and compare it with the previous results obtained using pure methanol. Using a $2 \mathrm{~g} \mathrm{~L}^{-1}$ total feed concentration of an equimolar mixture of the four stereoisomers of nadolol, the more retained component was fully recovered $(100 \%$ purity and $100 \%$ recovery), with a system productivity of $0.77 \mathrm{~g} \mathrm{~L}^{-1}$ hour $^{-1}$ and a solvent consumption of $9.62 \mathrm{~L} \mathrm{~g}^{-1}$. Comparing these results with the ones previously reported using 100:0.1 methanol-diethylamine solvent composition, this work shows that the 25:75:0.1 methanol-acetonitrile-diethylamine is a better alternative for the preparative separation of nadolol stereoisomers by SMB chromatography. These results are confirmed by simulation of the SMB operation for higher feed concentrations, by comparing the performances of the two solvent compositions using the data obtained experimentally through the measurement of the adsorption equilibrium isotherms and the kinetic data obtained for both solvents. The new experimental and simulation results stress out that the performance of the preparative separation can be improved by a careful selection of the solvent composition.
\end{abstract}

\section{KEYWORDS}

Chiralpak IA, nadolol stereoisomers, optimization of solvent composition, simulated moving bed

\section{1 | INTRODUCTION}

The preparative chiral separation of nadolol stereoisomers by SMB technology was studied in few recent works. In 2013, Ribeiro et $\mathrm{al}^{1}$ reported an upgrade in the analytical separation of all the four stereoisomers of nadolol, firstly reported by McCarthy ${ }^{2}$ in 1994, by replacing hexane by heptane in an alcohol-hydrocarbon solvent. Furthermore, that work reported the first experimental SMB preparative separation of the more retained stereoisomer (RSR- nadolol), referred as the one responsible for the therapeutic action of nadolol drug. ${ }^{3}$ In this pseudobinary separation, the more retained stereoisomer was collected in the SMB extract outlet stream, while the other three stereoisomers coeluted and were collected in the raffinate outlet stream. The separation was performed using a solvent composition of 80:20:0.3 ( $v / v / v)$ ethanol-heptanediethylamine and a coated Chiralpak AD chiral stationary phase (CSP). In 2015, Jermann et $\mathrm{al}^{4}$ also reported the nadolol separation using a three-column intermittent 
simulated moving bed chromatography (3C-ISMB) with a 40:60:0.3 $(v / v / v)$ ethanol-heptane-diethylamine solvent composition and the same Chiralpak AD CSP.

More recently, in 2016, Arafah et $\mathrm{al}^{5}$ presented the pseudobinary separation of the RSR stereoisomer of nadolol, using the immobilized Chiralpak IA CSP. A very extensive screening of CSP-solvent combinations was presented, and for the same $(1+2+3) / 4$ pseudobinary preparative separation, a set of six possible solvent compositions were suggested. Taking into account a good selectivity, a high solubility of the solute and the industrial advantage of working with a pure solvent, pure methanol (with 0.1 diethylamine), was used to perform the referred experimental SMB separation. That work proved that the immobilized Chiralpak IA is a very interesting alternative to the former coated Chiralpak $\mathrm{AD}$ CSP, since it extends the range of compatibility between adsorbent and solvent compositions, ${ }^{6-9}$ promoting new possibilities for preparative separation of nadolol stereoisomers. It should be emphasized that these chiral adsorbents are still the most used ones for preparative chiral separations due to their high loading capacities.

The choice of the best solvent composition generally results from a trade-off between different factors that contribute to higher system productivity, namely, high selectivity, short retention times, and high linearity of the adsorption equilibrium isotherms, besides high solubility of the solute. In this work, an alternative solvent composition of 25:75:0.1 methanol-acetonitrile-diethylamine is used with the same Chiralpak IA CSP. The results obtained in this work and its comparison with the ones obtained with pure methanol show clearly how a higher linearity of the adsorption equilibrium isotherms, with similar selectivity, can allow a significant improvement in the SMB system performance. This comparison will be presented and discussed by means of different experimental and simulation results, namely, through pulse and breakthrough experiments, adsorption equilibrium isotherm measurements, and SMB operation.

\section{2 | EXPERIMENTAL}

\section{1 | Chemicals}

The mixture of the four nadolol stereoisomers of nadolol and 1,2,3-tri-tert-butylbenzene, used as the nonretained compound, were both obtained from Sigma-Aldrich (Schnelldorf, Germany). The basic modifier diethylamine (DEA), methanol (M), and acetonitrile (ACN), all HPLC grade solvents, were obtained from Fluka (Buchs, Switzerland). All reagents and solvents were used without further purification.

\section{2 | Equipment for analytical and preparative chromatography}

Two Knauer HPLC systems were used to perform elution chromatography, experimental measurements of the adsorption equilibrium isotherms, and breakthrough experiments.

The analytical Knauer HPLC system was equipped with a Smartline UV detector 2520 set at 270 -nm wavelength, one Smartline 1050 pump with a $10-\mathrm{mL}$ pump head, and a manual injection valve with a $20-\mu \mathrm{L}$ loop. Analytical chromatography measurements were performed using a Chiralpak IA column of analytical dimensions $(250 \mathrm{~mm} \mathrm{~L} \times 4.6 \mathrm{~mm}$ ID) packed with a $5-\mu \mathrm{m}$ particle size material.

The preparative Knauer HPLC system was equipped with a Smartline UV detector 2520 set at 270 -nm wavelength, two Smartline 1050 pumps with 50-mL pump heads, and a manual six-port/three-channel injection valve with a $1000-\mu \mathrm{L}$ loop. Loading and preparative experiments were carried out using seven preparative SMB columns $(100 \mathrm{~mm} \mathrm{~L} \times 21.0 \mathrm{~mm}$ ID). These columns were home-packed with Chiralpak IA bulk material of a 20- $\mu \mathrm{m}$ particle size diameter. The chiral stationary phase Chiralpak IA (3,5-dimethylphenylcarbamate polymer derivative) is commercially available from Daicel Technologies Europe (Illkirch, France). The home-packing of the seven SMB columns was carried out using a Knauer Wellchrom pneumatic pump K-1900 equipped with a $250 \mathrm{~mL}$ minute $^{-1}$ pump head and using isopropanol as packing solvent.

\section{3 | SMB pilot unit}

The pseudobinary separation of nadolol stereoisomers was performed using a pilot SMB unit, completely designed and built at the LSRE-LCM group and designated as FlexSMB-LSRE. Six columns were used to operate the unit with a classic [1-2-2-1] configuration. Both extract and raffinate outlet streams required two selected dead-end (SD) flow path, one SD valve in the feed and eluent streams, and six two-way valves, one per each column. Four HPLC pumps (VWR International, Radnor, PA), three with pump heads of $50 \mathrm{~mL}$ minute $^{-1}$ and one with a $10 \mathrm{~mL}$ minute ${ }^{-1}$ pump head, were assisted by two Coriolis flow meters (Bronkhorst High-Tech, Ruurlo, Netherlands): one measuring the flow rate at the inlet of section II (after the extract outlet), the other measuring the extract outlet flow rate. A complete and detailed description of the FlexSMB-LSRE pilot unit can be found in previous published LSRE works. ${ }^{1,10,11}$ 


\section{3 | METHODOLOGY}

\section{1 | Packing and testing the SMB columns}

A proper packing of the preparative columns is one important step since good separation performances also depend on the adequate and similar hydrodynamic behavior of all the chromatographic columns. Seven SMB columns were packed with the same Chiralpak IA $20-\mu \mathrm{m}$ bulk material, and using pure isopropanol as the packing solvent. The quality of all the SMB columns' packing was validated through elution chromatographic experiments, using the nonretained compound and the nadolol mixture. The efficiency of the SMB columns was also evaluated by measuring the influence of the superficial velocity, $u_{o}=Q / A$, upon the height equivalent to a theoretical plate, HETP $=\sigma^{2} \mathrm{~L} / \mu_{1}^{2}$ (where $Q$ is the flow rate, $A$ the column section area, $L$ the column length, $\sigma$ the peak variance, and $\mu_{1}$ the first moment of the chromatographic peak).

\section{2 | Preparative experiments}

The mobile phase composition of 25:75:0.1 methanolacetonitrile-diethylamine was selected based on the experimental results previously obtained and published by Arafah et al. ${ }^{5}$ The reader is invited to read and confer the results presented in Figure 4 of the referred publication. Those results represent six possible solvent compositions to be used to achieve the $(1+2+3) / 4$ pseudobinary separation of the more retained stereoisomer of nadolol. To confirm the same adsorption behavior, a new set of elution chromatographic pulses of a $10 \mathrm{~g} \mathrm{~L}^{-1}$ nadolol solution were carried out in a SMB column for both the 25:75:0.1 methanol-acetonitrilediethylamine and the 100:0.1 methanol-diethylamine solvent compositions.

\section{3 | Tools for modeling and simulation}

The experimental determination of the competitive adsorption isotherms was carried out using the adsorption-desorption method. More details related to this methodology can be founded elsewhere. ${ }^{12,13}$ The Langmuir model is often used to describe the adsorption behavior. However, for chiral mixtures, this model usually fails in the prediction of the preparative separation process. It is well known that the selectivity factor decreases with the increase of the species concentration. The Langmuir model does not consider this behavior since it predicts a constant value over the entire range of concentrations. A practical way to overcome this limitation is to add a linear term to the Langmuir model.

For the 25:75 methanol-acetonitrile composition, the three less retained species coelute with very similar retention times, so the following competitive linear + Langmuir model was found to better describe the adsorption behavior:

$$
\mathrm{q}_{\mathrm{i}}^{*}=\mathrm{mC}_{\mathrm{i}}+\frac{\mathrm{Qb}_{123} \mathrm{C}_{\mathrm{i}}}{1+\mathrm{b}_{123}\left(\mathrm{C}_{1}+\mathrm{C}_{2}+\mathrm{C}_{3}\right)+\mathrm{b}_{4} \mathrm{C}_{4}}
$$

considering the three less retained stereoisomers, and

$$
\mathrm{q}_{4}^{*}=m C_{4}+\frac{\mathrm{Qb}_{4} \mathrm{C}_{4}}{1+\mathrm{b}_{123}\left(\mathrm{C}_{1}+\mathrm{C}_{2}+\mathrm{C}_{3}\right)+\mathrm{b}_{4} \mathrm{C}_{4}}
$$

for the more retained stereoisomer, where $\mathrm{q}_{\mathrm{i}}^{*}$ and $C_{i}$ are, respectively, the solid and the liquid concentrations of component $i$ and $m, Q, b_{123}$, and $b_{4}$ are the adsorption equilibrium isotherm parameters. These parameters were estimated using the Levenberg-Marquardt algorithm.

Fixed-bed experiments were performed to validate the adsorption equilibrium isotherm model by comparing the experimental and the theoretical breakthrough chromatographic curves (saturation and regeneration steps). These experiments were also used to estimate kinetic data, ie, axial dispersion and mass transfer resistance. When dealing with preparative chiral separations, it is normally accepted the use of a linear driving force (LDF) model to describe the mass transfer phenomena. ${ }^{14}$ The fixedbed adsorption behavior was predicted by simulation, using the PDECOL package based on the method of orthogonal collocation in finite elements.

The transient SMB model was used to predict the SMB operation conditions. This model takes into account axial dispersion, mass transfer resistance, the FlexSMB unit's dead volumes, and the consequent corrective switching time delay. ${ }^{11}$ The simulations were carried out using the gPROMS software package (v.3.0.4) from Process System Enterprise (UK), being the flow rates for sections II and III chosen inside the separation region defined by the equilibrium theory. ${ }^{15,16}$

The main SMB performance parameters are purity, recovery, system productivity, and solvent consumption. Both SMB extract and raffinate outlet streams must satisfy the purity and recovery specifications. The main objective of the present pseudobinary separation is to obtain the target compound (the more retained stereoisomer) in a pure form. It is assumed that the more retained compound will be completely recovered in the extract stream, while the other three compounds will coelute and be completely recovered in the raffinate stream. According to these assumptions, the extract purity (PUX, \%) is defined as the ratio between the mean 
concentration of the more retained compound and the sum of the mean concentrations of all the four compounds in the extract stream,

$$
\text { PUX }=\frac{<\mathrm{C}_{4}^{\mathrm{X}}>}{\sum_{\mathrm{i}=1}^{4}<\mathrm{C}_{\mathrm{i}}^{\mathrm{X}}>}
$$

Similarly, the raffinate purity (PUR, \%) is defined as the ratio between the sum of the mean concentration of the three less retained compounds and the sum of the mean concentrations of all the four compounds in the raffinate stream,

$$
\mathrm{PUR}=\frac{\sum_{\mathrm{j}=1}^{3}<\mathrm{C}_{\mathrm{j}}^{\mathrm{R}}>}{\sum_{\mathrm{i}=1}^{4}<\mathrm{C}_{\mathrm{i}}^{\mathrm{R}}>}
$$

The recovery in the extract stream (RCX, \%) is defined as the ratio between the amount of the more retained compound obtained in the extract and the total amount of the same compound fed to the system,

$$
\mathrm{RCX}=\frac{\mathrm{QX}_{\mathrm{X}}<\mathrm{C}_{4}^{\mathrm{X}}>}{\mathrm{Q}_{\mathrm{F}}<\mathrm{C}_{4}^{\mathrm{F}}>}
$$

The system productivity (PR, g target product $\mathrm{L}_{\text {bed }}{ }^{-1} \mathrm{~h}^{-1}$ ) is defined as the amount of the target compound obtained in the extract outlet stream per total volume of bed and per time,

$$
\mathrm{PR}=\frac{\mathrm{Q}_{\mathrm{X}}<\mathrm{C}_{4}^{\mathrm{X}}>}{\mathrm{V}_{\mathrm{T}}}
$$

The solvent consumption (SC, $\mathrm{L}_{\text {solvent }} \mathrm{g}_{\text {target product }}{ }^{-1}$ ) is defined as the ratio between the total amount of solvent fed to the system (eluent and feed) and the amount of the target compound collected in the extract outlet stream,

$$
\mathrm{SC}=\frac{\mathrm{Q}_{\mathrm{E}}+\mathrm{Q}_{\mathrm{F}}}{\mathrm{Q}_{\mathrm{X}}<\mathrm{C}_{4}^{\mathrm{X}}>}
$$

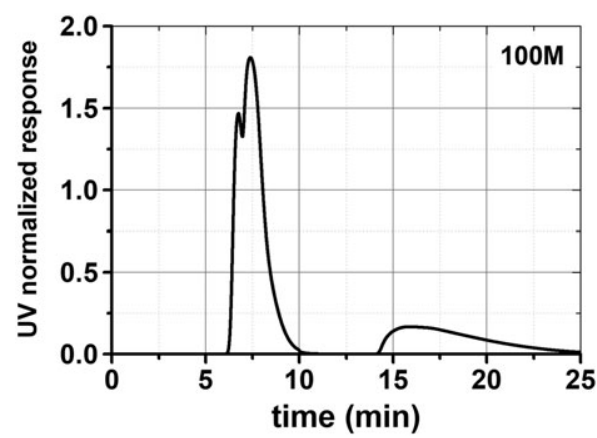

More information about the methodology and model equations used for fixed-bed and SMB modeling and simulation can be found in previously published works. ${ }^{1,17,18}$

\section{4 | RESULTS AND DISCUSSION}

\section{1 | Loading pulses}

As it was mentioned before, when choosing the solvent composition, there is a trade-off that must be settled between high selectivity and short retention times. In order to confirm the results previously obtained using both the pure methanol and the methanol-acetonitrile solvents, elution pulses were carried out with one SMB column. To approach the preparative and production conditions, a big injection volume $(1000 \mu \mathrm{L})$ and a high nadolol feed concentration $\left(10 \mathrm{~g} \mathrm{~L}^{-1}\right)$ were used. The obtained results are presented in Figure 1 and confirm the previously published results by Arafah et al. ${ }^{5}$

The pure methanol composition allows high selectivity values between the more retained compound and the three less retained compounds. However, the use of this solvent also introduces a higher nonlinearity (peak tailing) for the more retained compound, when compared with the behavior found for the 25:75 methanolacetonitrile solvent. The use of this 25:75 methanolacetonitrile composition, despite representing a loss in selectivity, allows a significant reduction in retention time and peak tailing for the more retained species, which can lead to a significant enhancement of system productivity, mainly at high feed concentrations. This behavior should be further explored and checked by measuring the adsorption equilibrium isotherms and through breakthrough experiments.

\subsection{Adsorption equilibrium isotherms}

The adsorption equilibrium isotherms of the nadolol mixture were measured experimentally using the adsorption-

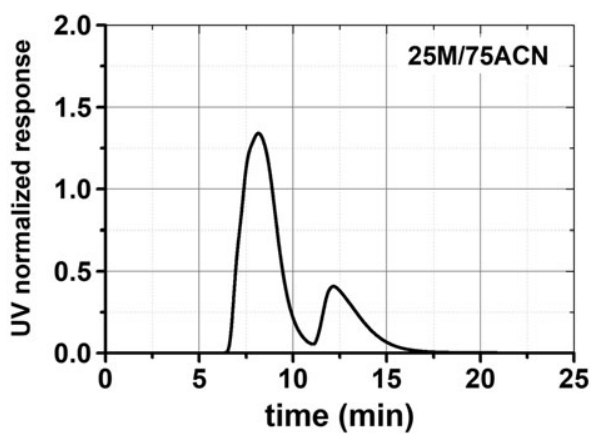

FIGURE 1 UV-normalized response to a pulse of nadolol using a mobile phase composition of 100:0.1 methanol-diethylamine (left) and 25:75:0.1 methanol-acetonitrile-diethylamine (right) in one SMB column $\left(C_{F}^{T}=10.0 \mathrm{~g} \mathrm{~L}^{-1} ; Q=5.0 \mathrm{~mL} \mathrm{~min}^{-1}\right.$; injection volume $\left.=1000 \mu \mathrm{L}\right)$ 
desorption method. The equilibrium data were experimentally measured for the 25:75 methanol-acetonitrile solvent composition, using a SMB column and five nadolol feed concentrations $\left(2,4,6,8\right.$, and $\left.10 \mathrm{~g} \mathrm{~L}^{-1}\right)$. The previously presented linear + Langmuir model was used to fit the experimental adsorption equilibrium data. The obtained results are presented in Figure 2 (left) and show a good agreement between experimental data (points) and the predicted adsorption equilibrium behavior (lines). It should be pointed out that, using the 25:75 methanol-acetonitrile solvent composition, the three less retained nadolol components overlap with very similar retention times, and so, they were considered to elute together. The obtained model parameters are $m=0.6947$, $Q=5.874 \mathrm{~g} \mathrm{~L}^{-1}, b_{123}=2.449 \times 10^{-2} \mathrm{~L} \mathrm{~g}^{-1}$, and $b_{4}=1.547 \times 10^{-1} \mathrm{~L} \mathrm{~g}^{-1}$, with a normalized standard deviation of $\mathrm{SD}=0.134$. Comparing these results with the ones obtained for pure methanol, ${ }^{5}$ it can be concluded that the 25:75 methanol-acetonitrile solvent presents a higher linearity of the adsorption equilibrium isotherm, particularly for the more retained component 4 (a $b_{4}=1.547 \times 10^{-1} \mathrm{~L} \mathrm{~g}^{-1}$ versus a $b_{4}=4.379 \times 10^{-1} \mathrm{~L} \mathrm{~g}$ ${ }^{-1}$ for the pure methanol solvent).

Figure 2 (right) presents the experimental and the predicted values of selectivity as a function of the nadolol feed concentration. Comparing these results with the ones reported for pure methanol, ${ }^{5}$ it can be stressed out that the initial higher selectivity using pure methanol (2.1 versus 1.9) does not remain at high nadolol feed concentration. In fact, going from a diluted to a $10 \mathrm{~g} \mathrm{~L}^{-1}$ feed solution, the loss in selectivity between the more and the other three less retained components is less pronounced using the 25:75 methanol-acetonitrile solvent (from 1.9 to 1.6 for $25: 75$ methanol-acetonitrile versus from 2.1 to 1.5 for pure methanol). Therefore, it is expected the 25:75 methanol-acetonitrile solvent composition will allow an improvement in the preparative performance of the $(1+2+3) / 4$ pseudobinary separation.

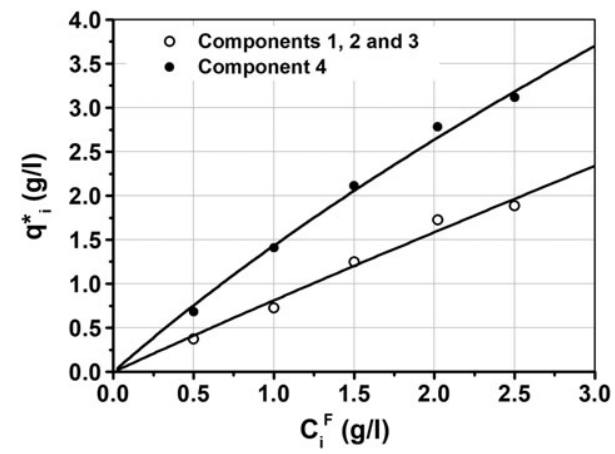

\section{3 | SMB column efficiency}

After packing, all SMB columns were tested to evaluate the packing quality through pulses and breakthrough measurements. One SMB column was selected to perform the HETP measurements. This study was carried out by injecting a $2.0 \mathrm{~g} \mathrm{~L}^{-1}$ nadolol solution using three different flow rates $\left(5,10\right.$, and $\left.15 \mathrm{~mL} \mathrm{~min}^{-1}\right)$. The obtained results are presented in Figure 3 for both the pure methanol and the 25:75 methanol-acetonitrile solvent compositions. These results show that HETP for the more retained compound remains constant using 25:75 methanolacetonitrile $(400 \mu \mathrm{m})$, while increases for pure methanol (from 400 to $700 \mu \mathrm{m}$ ). This is an additional indication that 25:75 methanol-acetonitrile can lead to better separation performances, particularly at preparative conditions (high flow rates and feed concentrations).

\section{4 | Fixed-bed adsorption behavior}

In order to study the fixed-bed adsorption behavior and to validate the linear + Langmuir adsorption equilibrium isotherm model, breakthrough measurements (saturation and regeneration) were performed. The prediction of the axial dispersion was carried out using the nonretained compound leading to a Peclet number of 1000; a nadolol feed solution was used to predict a value for mass transfer resistance of $k=1.0$ second $^{-1}$. Figure 4 presents the experimental (points) and the predicted results by the selected adsorption equilibrium isotherm model (lines).

It can be concluded that there is a good agreement between the experimental adsorption behavior (points) and the one predicted using the selected linear + Langmuir model (lines). Comparing the results presented in Figure 4 with those previously published for the pure methanol solvent composition, ${ }^{5}$ it can be confirmed the higher retention time of the more retained compound.

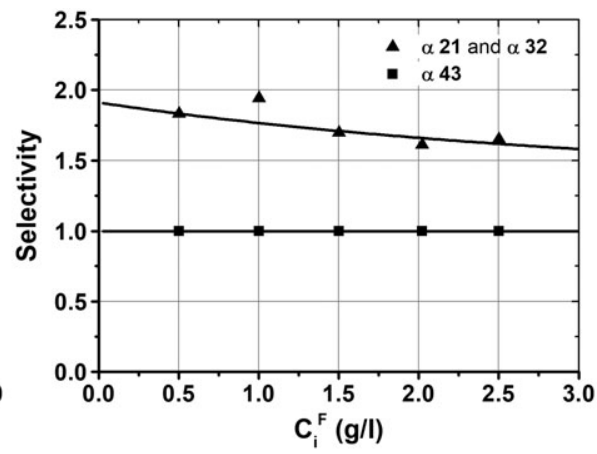

FIGURE 2 Comparison between experimental and model results on the adsorption equilibrium isotherms for nadolol stereoisomers using 25:75:0.1 methanol-acetonitrile-diethylamine solvent composition. Figure 2 (left), for the multicomponent adsorption equilibrium isotherms and its fitting to a linear + Langmuir competitive model, Equations 1 and 2. Figure 2 (right), for the selectivity between the different nadolol stereoisomers as a function of feed concentration and its fitting to the same linear + Langmuir competitive model 

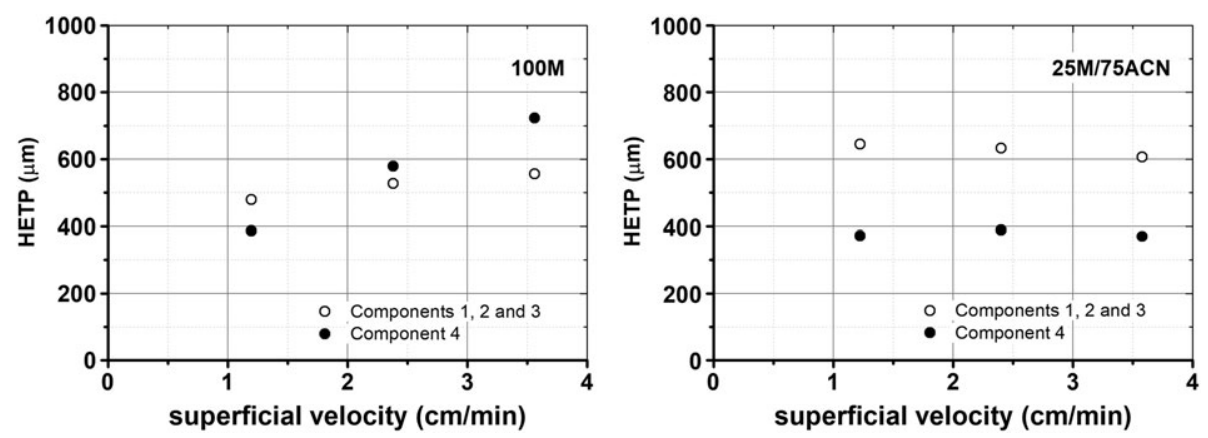

FIGURE 3 Height equivalent to a theoretical plate (HETP) as a function of superficial velocity for a SMB home-packed column using a mobile phase composition of methanol-diethylamine 100:0.1 (left) and 25:75:0.1 methanol-acetonitrile-diethylamine (right). Open and closed circles for the three less and the more retained nadolol stereoisomers, respectively. $\left(C_{F}{ }^{T}=2.0 \mathrm{~g} \mathrm{~L}^{-1} ; Q=5,10\right.$, and $15 \mathrm{~mL} \mathrm{~min}^{-1}$; injection volume $=100 \mu \mathrm{L}$ )
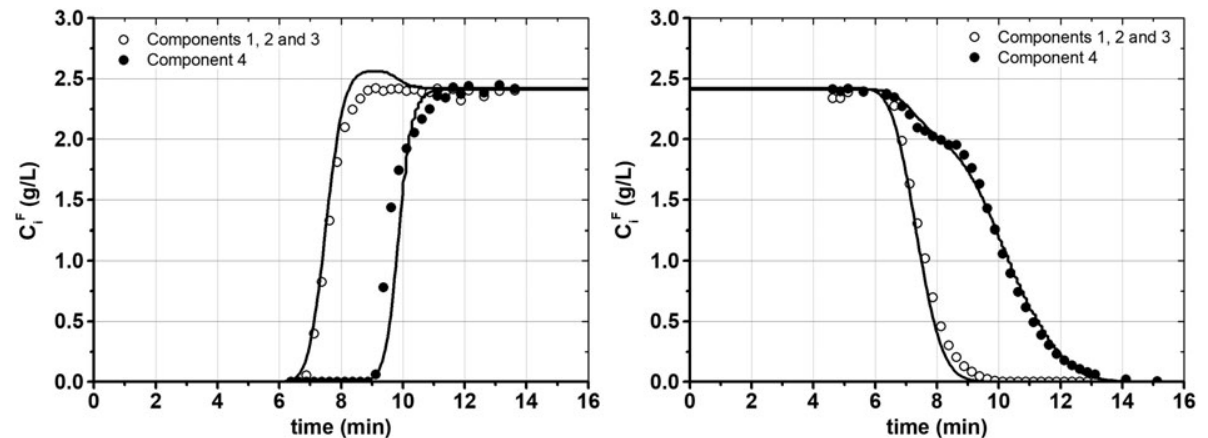

FIGURE 4 Saturation (adsorption) and regeneration (desorption) curves for a $9.7 \mathrm{~g} \mathrm{~L}^{-1}$ nadolol racemic feed concentration and a 25:75:01 methanol-acetonitrile-diethylamine solvent composition. Comparison between experimental (points) and simulation (lines) results. Flow rate: $5 \mathrm{~mL}$ minute ${ }^{-1}$. Model parameters: $\varepsilon=0.4$; Peclet number $(\mathrm{Pe})=1000 ; k=1.0$ second $^{-1}$, and the linear + Langmuir model parameters

But, more significantly, the roll-up phenomenon for the three less retained species using the 25:75 methanolacetonitrile solvent is strongly reduced (almost inexistent at the obtained experimental data), as well as the tailing for the more retained component at the desorption step. These are, once again, both clear signs of the less nonlinearity of the adsorption equilibrium isotherm using the 25:75 methanol-acetonitrile solvent.

\subsection{SMB pseudobinary separation}

The experimental pseudobinary separation of the nadolol stereoisomers was performed in the FlexSMBLSRE pilot unit. In order to avoid the damage of the stationary phase, a maximum pressure drop of 35 bar was set at section I, representing, for the 25:75 methanolacetonitrile solvent composition, a maximum flow rate of $Q_{I}^{*}=35 \mathrm{~mL}$ minute ${ }^{-1}$. The SMB operating conditions were predicted based in the equilibrium theory applied to nonlinear systems. ${ }^{15} \mathrm{~A}$ detailed description of the methodology used in the definition of the SMB operating conditions can be found elsewhere. ${ }^{1}$ Figure 5 presents

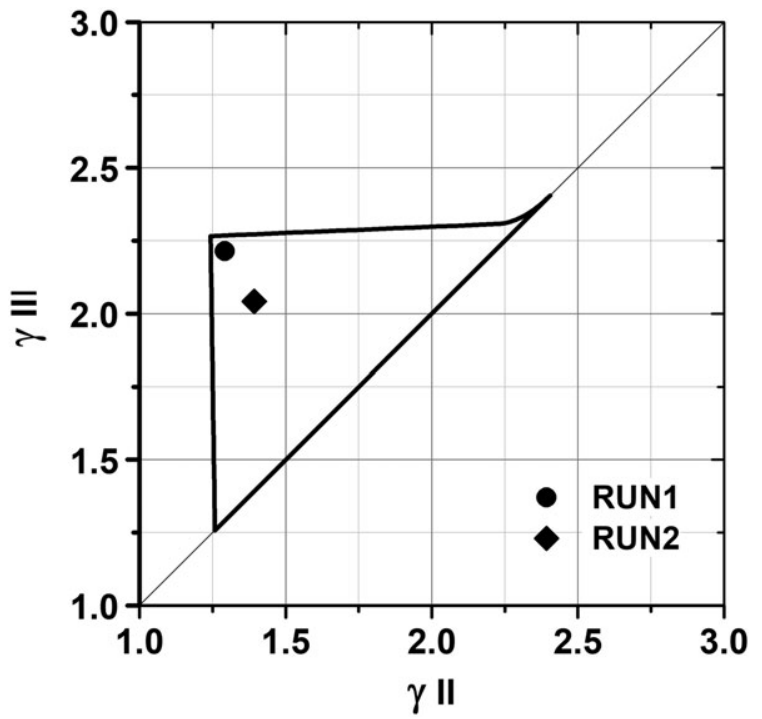

FIGURE 5 SMB complete separation region (equilibrium theory) and experimental SMB operating points (RUN1 and RUN2) for the pseudobinary separation of the more retained nadolol stereoisomer, using Chiralpak IA CSP, the 25:75:0.1 methanol-acetonitrilediethylamine solvent composition and a $2 \mathrm{~g} \mathrm{~L}^{-1}$ nadolol feed concentration 
the predicted region of complete separation for a feed solution of $2 \mathrm{~g} \mathrm{~L}^{-1}$, as well as the experimentally measured $\gamma_{\mathrm{III}} \mathrm{X} \gamma_{\mathrm{II}}$ points for the two SMB experimental runs.

The unit was operated using a conventional SMB mode with a [1-2-2-1] configuration. The extract and the recycle flow rates were measured and monitored by means of two Coriolis flow meters. The extract and raffinate flow rates were also monitored by means of the total weighted recovered mass in each outlet over each complete cycle. This procedure was carried out for all the 28 cycles of SMB experimental operation. The extract and the raffinate collected samples were analyzed by HPLC to evaluate the concentrations of all the four stereoisomers in the outlet streams.

Figure 6 presents the transient evolution of the nadolol stereoisomer concentrations in the extract and raffinate outlet streams during SMB operation for both runs: RUN1 from initial to cycle 9 and RUN2 from the end of cycle 9 to cycle 28 (RUN2 started from the achieved cyclic steady state of RUN1). The cyclic steady state for RUN2 was considered to be obtained when both the extract and the raffinate concentrations do not change more than 5\% during five successive cycles. At that point, several samples were collected and analyzed to obtain the internal concentration profiles, using a six-port valve installed after the end of section IV. These samples were collected at different intervals $(25 \%, 50 \%, 75 \%$, and $90 \%)$ of the switching time.

Figure 7 presents the experimental (points) and simulated (lines) internal concentration profiles at the cyclic steady state of SMB operation (cycles 20, 22, 24, and 26). It should be pointed out that the presented internal profiles show two small plateaus near the extract and raffinate outlets due to the dead volumes of the FlexSMB-

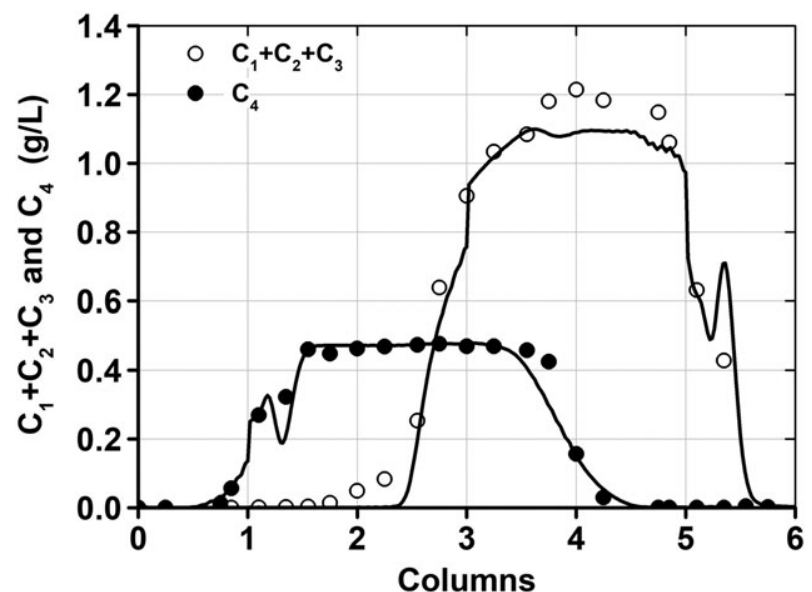

FIGURE 7 Experimental (points) and predicted (lines) internal concentration profiles at the cyclic steady state during the SMB operation (RUN2; cycles 20, 22, 24, and 26). Open and closed circles for the total three less retained and the more retained stereoisomer, respectively. Model parameters used as in Figure 6

LSRE pilot unit that are also taken into account in the simulation and control software.

The main SMB experimental operating conditions and performance parameters are presented in Table 1 (internal and external flow rates, switching time, and the corresponding $\gamma$ values defined for the equivalent true moving bed operation).

RUN1 allowed a maximum system productivity of $0.84 \mathrm{~g} \mathrm{~L}^{-1}$ hour $^{-1}$. However, this run led to both extract and raffinate outlet-contaminated streams due to the incomplete recovery of the more retained compound in the extract and the incomplete recovery of the three less retained species in the raffinate. In order to achieve a complete separation, a second run was carried out,
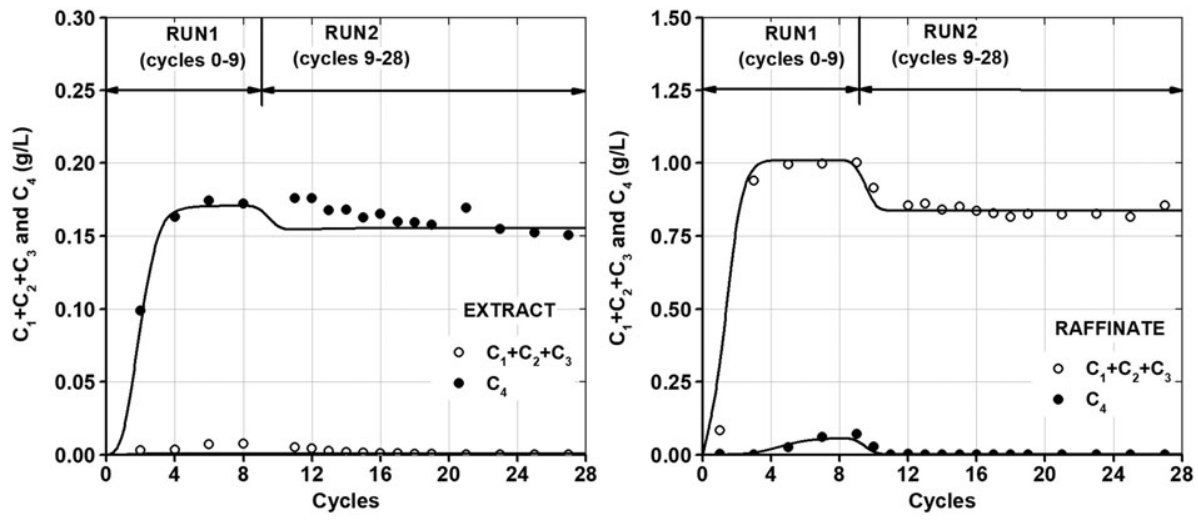

FIGURE 6 Experimental (points) and predicted (lines) transient evolution of the nadolol stereoisomer concentrations in both the extract (left) and raffinate (right) outlet streams for the two SMB runs: RUN1 from initial to cycle 9 and RUN2 from the end of cycle 9 to cycle 28 (RUN2 started from the achieved cyclic steady state of RUN1). Open and closed circles for the total three less retained and the more retained stereoisomer, respectively. Model parameters used: bed porosity, $\varepsilon=0.4$; mass transfer coefficients, $k=1.0$ second $^{-1}$; Pe $=1000$; and linear + Langmuir isotherm parameters 
TABLE 1 SMB experimental runs for the pseudobinary separation of the more retained nadolol stereoisomer using the FlexSMB-LSRE pilot unit with Chiralpak IA CSP and 25:75:0.1 methanol-acetonitrile-diethylamine solvent composition

\begin{tabular}{|c|c|c|c|c|c|}
\hline RUN & $C_{F}^{T}, g^{-1}$ & $\begin{array}{l}\text { Internal Flow } \\
\text { Rates, } \mathrm{mL} \text { min }^{-1}\end{array}$ & $\begin{array}{l}\text { External Flow Rates, } \\
\mathrm{mL} \mathrm{min}^{-1}\end{array}$ & TMB $\gamma$ Values & Performance Parameters \\
\hline 1 & 2.00 & $\begin{array}{l}Q_{I}^{*}=34.4 \\
Q_{I I}^{*}=17.4 \\
Q_{I I I}^{*}=24.4 \\
Q_{I V}^{*}=13.8 \\
t^{*}=1.82 \mathrm{~min}\end{array}$ & $\begin{array}{l}Q_{E}=20.4 \\
Q_{F}=7.00 \\
Q_{X}=16.9 \\
Q_{R}=10.6 \\
Q_{R E C}=14.0\end{array}$ & $\begin{array}{l}\gamma_{I}=3.5221 \\
\gamma_{I I}=1.2920 \\
\gamma_{I I I}=2.2125 \\
\gamma_{I V}=0.8181\end{array}$ & $\begin{array}{l}\mathrm{PUX}=95.9 \% \\
\mathrm{PUR}=93.3 \% \\
\mathrm{RCX}=93.1 \% \\
\mathrm{PR}=0.84 \mathrm{~g} \mathrm{~L}^{-1} \mathrm{~h}^{-1} \\
\mathrm{SC}=9.43 \mathrm{~L} \mathrm{~g}^{-1}\end{array}$ \\
\hline
\end{tabular}

Performance parameters were experimentally measured during the whole cycle 9 for RUN1 and during the cyclic steady state obtained during cycles 20, 22, 24, and 26 for RUN2.
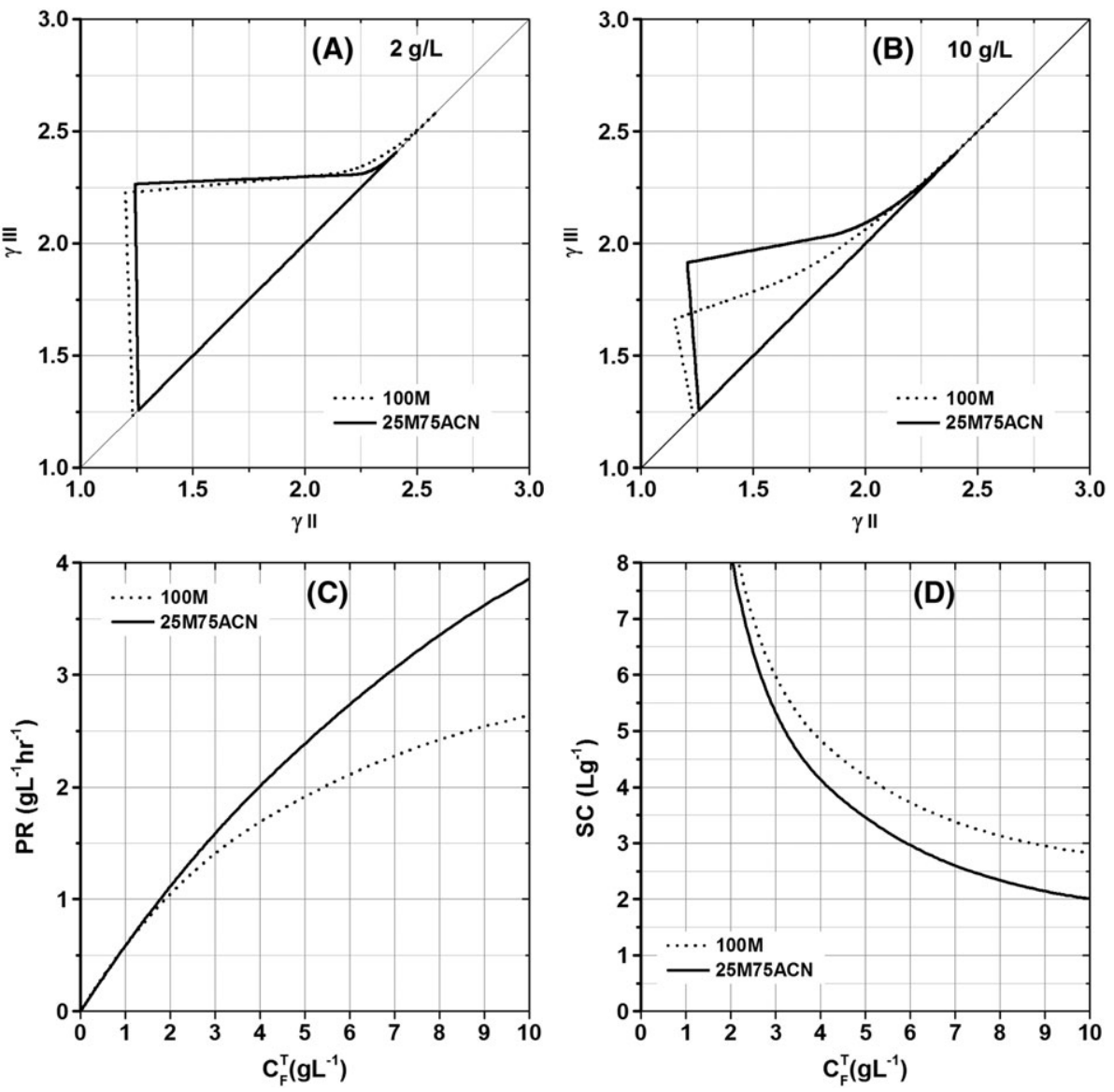

FIGURE 8 Prediction of the SMB performance for the pseudobinary separation of nadolol stereoisomers using 25:75 methanolacetonitrile (solid line) and pure methanol (dashed line) as solvents. Regions of complete separation (using equilibrium theory) for $2 \mathrm{~g} \mathrm{~L}^{-1} \mathrm{~A}$, and $10 \mathrm{~g} \mathrm{~L}^{-1} \mathrm{~B}$, and SMB system productivity $\mathrm{C}$, and solvent consumption $\mathrm{D}$, as a function of nadolol feed concentration

changing the $\gamma_{\mathrm{III}} \mathrm{X} \gamma_{\mathrm{II}}$ values to a point more inside the triangle. The experimental results obtained for RUN2 show that, for a $2 \mathrm{~g} \mathrm{~L}^{-1}$ feed solution, both extract and raffinate outlet streams were collected $100 \%$ pure (and with $100 \%$ recovery), with a system productivity of $0.77 \mathrm{~g} \mathrm{~L}^{-1}$ hour ${ }^{-1}$ and a solvent consumption of $9.62 \mathrm{~L} \mathrm{~g}^{-1}$. 
Using the pure methanol solvent and a nadolol feed concentration of $2 \mathrm{~g} \mathrm{~L}^{-1}$, for the complete separation (both purity and recovery of $100 \%$ ), the experimental reported values for system productivity and solvent consumption were $0.33 \mathrm{~g} \mathrm{~L}^{-1}$ hour ${ }^{-1}$ and $26.1 \mathrm{~L} \mathrm{~g}^{-1}$, respectively. ${ }^{5}$ In this way, the present work shows that the 25:75 methanolacetonitrile solvent allows better experimental performance parameters for the same $(1+2+3) / 4$ pseudoseparation.

These experimental results must be further validated and compared by simulation as both (the experiments of this work and the ones published by Arafah et $\mathrm{al}^{5}$ ) were obtained with SMB operating conditions away from the vertex points. The improvement of system productivity by using the 25:75 methanol-acetonitrile solvent composition instead of pure methanol was then confirmed by simulation. Figure $8 \mathrm{~A}$ and $8 \mathrm{~B}$ presents the predicted separation regions using a feed nadolol concentration of 2 and $10 \mathrm{~g} \mathrm{~L}^{-1}$, respectively. The correspondent vertex points of each triangle obtained by using the equilibrium theory correspond to the best system performance to be expected for a given feed concentration. Figure $8 \mathrm{~B}$ clearly shows that increasing the nadolol feed concentration to $10 \mathrm{~g} \mathrm{~L}$ ${ }^{-1}$, the system performance is significantly better using the 25:75 methanol-acetonitrile solvent than for pure methanol. The same conclusion can be extensively found at Figure $8 \mathrm{C}$ and 8D, where system productivity and solvent consumption (evaluated at the correspondent vertex points) are calculated as a function of the nadolol feed concentration for both solvent compositions. For instance, using a nadolol feed concentration of $10 \mathrm{~g} \mathrm{~L}$ -1 , the system productivity is $46 \%$ higher and the solvent consumption is $30 \%$ lower when using 25:75 methanolacetonitrile rather than pure methanol.

\section{5 | CONCLUSIONS}

The pseudobinary separation of the nadolol stereoisomers was performed by simulated moving bed technology. The preparative separation was performed using the immobilized Chiralpak IA adsorbent and a new 25:75:0.1 methanol-acetonitrile-diethylamine solvent composition. This work presents an important improvement of the SMB performance when compared with the previous results obtained with 100:0.1 methanol-diethylamine solvent. ${ }^{5}$ In this way, the present work stresses out that a proper selection and optimization of the solvent composition can represent an important improvement on the performance of the preparative separation process. Particularly, it shows that the selection of the solvent composition should not be based only on comparing selectivity in pulse experiments, and that a deeper analysis should be carried out by measuring and comparing the adsorption equilibrium isotherms and the performance of breakthrough experiments at high feed concentrations (the ones to be used at SMB operation).

The $(1+2+3) / 4$ pseudobinary separation of the most active stereoisomer of nadolol (RSR-nadolol) was performed using the FlexSMB-LSRE pilot unit. Using a feed solution of $2 \mathrm{~g} \mathrm{~L}^{-1}$, the more retained component was experimentally collected in the SMB extract outlet stream with a recovery and purity of $100 \%$, a system productivity of $0.77 \mathrm{~g} \mathrm{~L}^{-1}$ hour $^{-1}$, and a solvent consumption of $9.62 \mathrm{~L} \mathrm{~g}^{-1}$. Comparing these results with the ones previously published ${ }^{5}$ using pure methanol as solvent, it was observed an important increase in the experimental SMB performance parameters. This improvement was fully confirmed by simulation, using the experimental equilibrium and kinetic data, particularly at high feed concentrations. The less nonlinearity of the adsorption equilibrium isotherms for the 25:75 methanol-acetonitrile solvent leads to a smaller reduction of the SMB separation regions with the increase of the feed concentration, allowing better SMB performances when compared with the former pure methanol solvent.

The results presented in this work underlined the utmost importance of the proper choice of the solvent composition for SMB operation, based on a methodology using the experimental measurement of the adsorption equilibrium isotherms and kinetic data, together with simulation tools for the SMB operation, and how this optimization procedure should be carried out at preparative (production) conditions, ie, high flow rates and high feed concentrations.

\section{ACKNOWLEDGMENTS}

This work is a result of project “AIProcMat@N2020_ Advanced Industrial Processes and Materials for a Sustainable Northern Region of Portugal 2020," with the reference NORTE-01-0145-FEDER-000006, supported by Norte Portugal Regional Operational Programme (NORTE 2020), under the Portugal 2020 Partnership Agreement, through the European Regional Development Fund (ERDF), and of project POCI-01-0145-FEDER006984-Associate Laboratory LSRE-LCM funded by ERDF through COMPETE2020-Programa Operacional Competitividade e Internacionalização (POCI) - and by national funds through Fundação para a Ciência e a Tecnologia (FCT).

\section{ORCID}

Rami S. Arafah (1D) http://orcid.org/0000-0002-7743-4988 António E. Ribeiro (D) http://orcid.org/0000-0003-4569-7887 Alírio E. Rodrigues (D) http://orcid.org/0000-0002-0715-4761 Luís S. Pais (D) http://orcid.org/0000-0002-3000-2862 


\section{REFERENCES}

1. Ribeiro A, Rodrigues A, Pais L. Separation of nadolol stereoisomers by chiral liquid chromatography at analytical and preparative scales. Chirality. 2013;25(3):197-205.

2. McCarthy J. Direct enantiomeric separation of the four stereoisomers of nadolol using normal-phase and reversed-phase high-performance liquid chromatography with Chiralpak AD. J Chromatogr A. 1994;685(2):349-355.

3. Wang $X$, Ching CB. Liquid chromatographic retention behaviour and enantiomeric separation of three chiral center $\beta$-blocker drug (nadolol) using heptakis (6-azido-6-deoxy-2,3di-O-phenylcarbamated) $\beta$-cyclodextrin bonded chiral stationary phase. Chirality. 2002;14(10):798-805.

4. Jermann S, Meijssen M, Mazzotti M. Three column intermittent simulated moving bed chromatography: 3. cascade operation for center-cut separations. J Chromatogr A. 2015;1378:37-49.

5. Arafah R, Ribeiro A, Rodrigues A, Pais L. Separation of nadolol stereoisomers using Chiralpak IA chiral stationary phase. Chirality. 2016;28(5):399-408.

6. Kubota T, Yamamoto C, Okamoto Y. Preparation of chiral stationary phase based on immobilization of cellulose 3,5dimethylphenylcarbamate derivatives on silica gel. Chirality. 2003;15(1):77-82.

7. Zhang T, Kientzy C, Franco P, Ohnishi A, Kagamihara Y, Kurosawa H. Solvent versatility of immobilized 3,5dimethylphenylcarbamate of amylose in enantiomeric separations by HPLC. J Chromatogr A. 2005;1075(1-2):65-75.

8. Zhang T, Schaeffer M, Franco P. Optimization of a ca-sensitizing drug on an immobilized polysaccharide-based chiral stationary phase-case study with a preparative view. J Chromatogr A. 2005;1083(1-2):96-101.

9. Zhang T, Franco P, Nguyen D, et al. Complementary enantiorecognition patterns and specific method optimization aspects on immobilized polysaccharide-derived chiral stationary phases. J Chromatogr A. 2012;1269:178-188.
10. Sá Gomes P, Zabkova M, Zabka M, Minceva M, Rodrigues A. Separation of chiral mixtures in real SMB units: the FlexSMBLSRE. AIChE J. 2010;56:125-142.

11. Rodrigues A, Pereira C, Minceva M, et al. Simulated Moving Bed Technology: Principles, Design and Process Applications. Butterworth-Heinemann, Elsevier; 2015. ISBN:978-0-12802024-1.

12. Nicoud RM, Seidel-Morgenstern A. In: Nicoud RM, ed. Simulated Moving Beds, Basics and Application. Nancy: Institut National Polytechnique de Lorraine; 1993.

13. Seidel-Morgenstern A. Experimental determination of single solute and competitive adsorption isotherms. J Chromtogr A. 2004;1037(1-2):255-272.

14. Glueckauf E. Theory of chromatography. Trans Faraday Soc. 1955;51(0):1540-1551.

15. Storti G, Mazzotti M, Morbidelli M, Carrà S. Robust design of binary countercurrent adsorption separation processes. AIChE J. 1993;39(3):471-492.

16. Mazzotti M, Storti G, Morbidelli M. Optimal operation of simulated moving bed units for nonlinear chromatographic separations. J Chromatogr A. 1997;769(1):3-24.

17. Pais L, Rodrigues A. Design of simulated moving bed and varicol processes for preparative separations with a low number of columns. J Chromatogr A. 2003;1006(1-2):33-44.

18. Ribeiro A, Sá Gomes P, Pais L, Rodrigues A. Chiral separation of ketoprofen enantiomers by preparative and simulated moving bed chromatography. Sep Sci Technol. 2011;46(11):1726-1739.

How to cite this article: Arafah RS, Ribeiro AE, Rodrigues AE, Pais LS. Improving the performance of nadolol stereoisomers' preparative separation using Chiralpak IA by SMB chromatography. Chirality. 2019;31:62-71. https://doi.org/10.1002/ chir.23034 